\title{
Assessment of adnexal masses with Diffusion Weighted and dynamic contrast enhanced MR.
}

\author{
Ali Abdel Fattah Elsayed, ${ }^{1}$ MD, Salah Mohammed El Rays ${ }^{2}$, MD.
}

\section{* Corresponding Author: \\ Ali Abdel Fattah Elsayed \\ alyhelilamro@gmail.com}

\section{Received for publication January} 31, 2021; Accepted March 18, 2021; Published online March 18, 2021.

\section{Copyright 2020 The Authors published by Al-Azhar University, Faculty of Medicine, Cairo, Egypt. All rights reserved. This an open-access article distributed under the legal terms, where it is permissible to download and share the work provided it is properly cited. The work cannot be changed in any way or used commercially. \\ doi: 10.21608/aimj.2021.58914.1404. \\ ${ }^{1}$ Radiology Department, Faculty of Medicine, Al-Azhar University, Egypt. \\ ${ }^{2}$ Obstetrics and Gynecology Department, Faculty of Medicine, Mansoura University, Egypt.}

\begin{abstract}
Background: MRI used mainly in setting of sonographically heterogeneous adnexal mass, it can provide tissue characterization according to signal properties. It may not be possible to decide preoperatively whether conservative or radical surgery is appropriate for adnexal masses. DWI helps in discrimination between types of masses besides diagnosis of peritoneal implants.

Aim of the study: was studying the role of DW sequences and dynamic enhanced MRI regarding its diagnostic accuracy and also the DW ability images in accurate detection of lymphadenopathy.

Patients and Methods: Study was performed between November 2019 and March 2020 at Obied Hospital-KSA. carried on 20 patients with twenty masses. MR imaging pelvis was performed on (Achieva, Philips medical system) 1.5-T.(T2-T1-DW=DCE) Qantitative and qualitative statistical stastical analysis were performed.

Results: Twenty patients that revealed 20 complex adnexal masses selected after a preliminary pelvic ultrasound examination. The histopathology of the evaluated masses were (10 benign, 2 borderline, and 8 malignant). MRI, DWI and DCE were collectively resulting in differentiation of adnexal masses with high sensitivity of DWI, specificity of DCE.

Conclusion: DWI can add diagnostic value for MR criteria to differentiate types of adnexal lesions. DWI increased the sensitivity, but didn't improve the specificity or the accuracy, while addition of DCEMRI increased the specificity and accuracy

Keywords: adnexal masses, conventional MRI, dynamic enhanced MR, diffusion-weighted (DWI) imaging.
\end{abstract}

Disclosure: The authors have no financial interest to declare in relation to the content of this article. The Article Processing Charge was paid for by the authors.

Authorship: All authors have a substantial contribution to the article.

\section{INTRODUCTION}

MRI used mainly in setting of sonographically heterogeneous adnexal mass, it can provide tissue characterization according to signal properties. ${ }^{1}$

Adnexal masses remain the first indication for gynecologic surgery. Our goal is to minimize number of women unnecessarily undergoing cancer surgery. ${ }^{2}$

It may not be possible to decide preoperatively whether conservative or radical surgery is appropriate for adnexal masses. Pelvic MRI helps in difficult cases and may provide a more definitive diagnosis. MRI is utilized for detection the origin of the lesion and determine its content with has a high accuracy. Diffusion weighted imaging (DWI) helps in discrimination between types of masses besides diagnosis of peritoneal implants. ${ }^{3}$
When DWI revealed areas characterized by restricted diffusion or by low values of (Apparent Diffusion Coefficient) ADC generally correspond with foci of hypercellularity. Therefore, compatible with uncontrolled malignant proliferation. ${ }^{4}$

We studied the role of DW sequences and dynamic enhanced MRI, its diagnostic accuracy and also the ability DW images in accurate detection of lymphadenopathy.

\section{PATIENTS AND METHODS}

The current study is a prospective analysis that was conducted at Obeid hospital KSA (OBH) in the period from November 2019 to March 2020. 


\section{Patients:}

The study included 20 patients with twenty adnexal masses that fulfilled the inclusion criteria:

- Complex solid/cystic patterns.

- Vegetations and/or septations in cystic masses.

- Heterogeneous cystic masses

- $\quad$ Large mass size ( $\geq 5 \mathrm{~cm}$ in max. length).

\section{Exclusion criteria:}

- $\quad$ T1WI hyper intense lesions.

- T2WI very low hypo intense lesions are considered fibrous.

- Contra indications to MRI study.

They referred from the Gynecology department to the Women's imaging unit based on preliminary ultrasound examination used for cases selection.

The patients' age (22 to 62 year old) (mean 39.77).

The main complain of the cases was abdominal pain $(\mathrm{n}=10)$, and/or long standing abdominal enlargement $(n=5)$, other cases came with different complaints such as loss of weight.

\section{Methods:}

Patients referred to radiology department with preliminary US confirming the adnexal complex lesion.

MR imaging was performed on (Achieva, Philips medical system) 1.5-T. They imaged in supine position with the aid of pelvic phased-array coil. (SENSE XL Torso coil 16 channels).

\section{Patient preparation:}

Patients were instructed to fast for 6 hours and full bladder prior examination. MR Imaging protocol (Tab 1). Slice gap is one mm and flip angle 90 in all non-contrast sequences
Analysis of study:

- $\quad$ Pre-contrast images.

- Contrast enhancement.

- Wall thickness, presence of vegetations and/or mural enhancement.

- $\quad$ Presence of ascitis.

- $\quad$ Presence of pathologically enlarged pelvic or Para-aortic lymph nodes.

- Soft tissue infiltration.

- Omental deposit if present.

\section{DWI qualitative analysis:}

Our data analysis focused upon T2WI as base reference for mass detection. DWI high SI (diffusion restriction) in the solid components on different $b$ values $(0,500,1000$, and 1500$)$.

Matched ADC maps were applicable using also the available workstation: presence of bright SI on the ADC map stands for benign tissue, intermediate SI for malignant tissue and low to intermediate SI for fibrous /fatty tissue.

\section{Quantitative analysis:}

Manually plotted (ROI) was drawn at the part that showed hyperintensity, ROIs from 15 to $150 \mathrm{~mm}^{2}{ }^{5}$, $6,7,8$

\section{Statistical analysis:}

The MRI suggested pathology had been correlated with surgical pathology specimen being the reference.

Using computer software package SPSS 15.0 in the analysis. For quantitative variables, mean and standard deviation were presented. Frequency and percentages were presented for qualitative variables, all statistical parameters were calculated for the MRI and DWI. T-test was done to estimate differences in quantitative variables. $\mathrm{P}$ Value $<0.05$ is considered to be significant.

\begin{tabular}{|l|c|c|c|c|c|}
\hline \multicolumn{1}{|c|}{ Sequence } & TR(msec.) & TE(msec.) & FOV(mm) & Matrix & $\begin{array}{c}\text { Slice } \\
\text { thickness } \\
\text { (mm) }\end{array}$ \\
\hline T2 sagittal & & & & & \\
\hline T2 axial & 3000 & 90 & $290 \times 290$ & $208 \times 205$ & 4 \\
T1 axial & 3700 & 100 & $288 \times 350$ & $292 \times 180$ & 5 \\
T1 SPAIR axial & 500 & 10 & $260 \times 216$ & $263 \times 171$ & 5 \\
T2 coronal & 530 & 8 & $240 \times 240$ & $240 \times 190$ & 5 \\
\hline DWI (b & 5000 & 90 & $300 \times 300$ & $272 \times 200$ & 4.5 \\
0,500,1000,1500) & & 77 & $240 \times 240$ & $124 \times 100$ & 5 \\
DCE axial (THRIVE) & 2.8 & 9 & $370 \times 400$ & $512 \times 192$ & 1.5 \\
\hline
\end{tabular}

Table 1: The sequences of MRI study. 


\section{RESULTS}

20 patients that revealed 20 adnexal lesions selected after a preliminary pelvic ultrasound examination. The patients age range of 25 to 62 years ( $M=39.77$ +/-13.8 SD) showed benign lesions, while those their age ranged from 22 to 50 years $(M=39.625+/$ 10.676SD) showed malignant lesions. The histopathology of the evaluated masses were (10 benign, two borderline, and eight malignant) (Table 2).

The benign tumors were (two teratomas, two serous cystadenoma, two pedunculated subserous fibroid, one mucinous cystadenoma, one papillary serous cystadenofibroma,, one tubo-ovarian abscess, one pelvic abscess) (Figure 1).

Borderline tumor was: (borderline papillary serous cystadenoma). Malignant tumors included: (threecystadenocarcinoma, three mucinous cystadenocarcinoma, one juvenile granulosa cell tumor, one clear cell carcinoma) (Figure 2).

\begin{tabular}{|c|c|}
\hline Pathology & Frequency $\%$ \\
\hline Benign & $10(50 \%)$ \\
\hline Borderline & $2(10 \%)$ \\
\hline Malignant & $8(40 \%)$ \\
\hline Total & $20(100 \%)$ \\
\hline
\end{tabular}

Table 2: The pathological types included in the study.

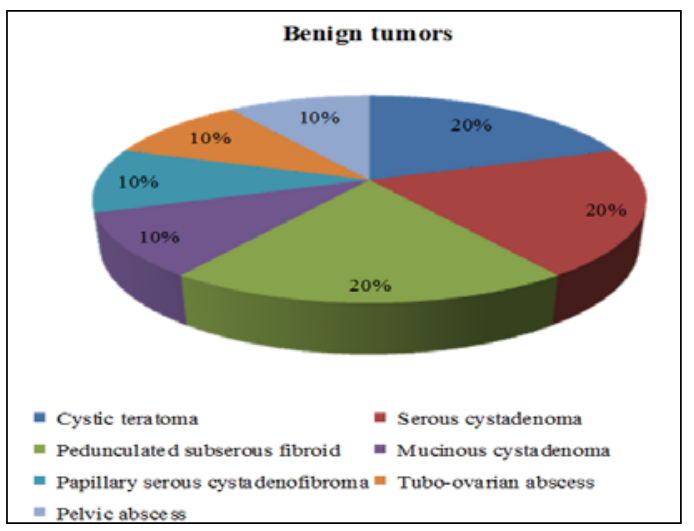

Fig 1: Benign tumors percentage.

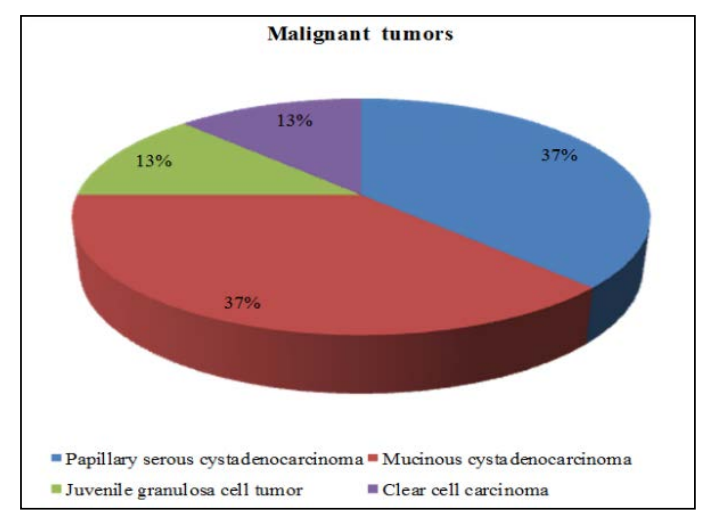

Fig 2: Malignant tumors percentage.
Most of the masses elicited intermediate intensity in T1 (70\%), some elicited subtle hyper intense signal (15\%), and mixed signal (15\%).(Figure 3).

Most of the masses elicited mixed intensity in T2(60\%), while the rest elicited bright signal intensity (40\%).(Figure 4).

The adnexal masses showed variable contrast uptake either early (30\%) or delayed (25\%) or no appreciable enhancement (45\%) (Figure 5).

Regarding the malignant masses: two of them showed wall thickness $>3 \mathrm{~mm}$ (25\%), four cases showed solid parts, vegetations $>1 \mathrm{~cm}(50 \%)$, two masses were associated with moderate ascites (25\%), and another two showed associate enhancing peritoneal nodules (25\%) (Figure 6).

Some masses revealed hyperintensity in DWI and were diagnosed as being malignant in spite of benign pathology, these masses included the following entities: 1) mature cystic teratoma(n=2), 2) tuboovarian abscess $(n=1)$ and 3 uterine fibroid $(n=1)$. (Table 3).

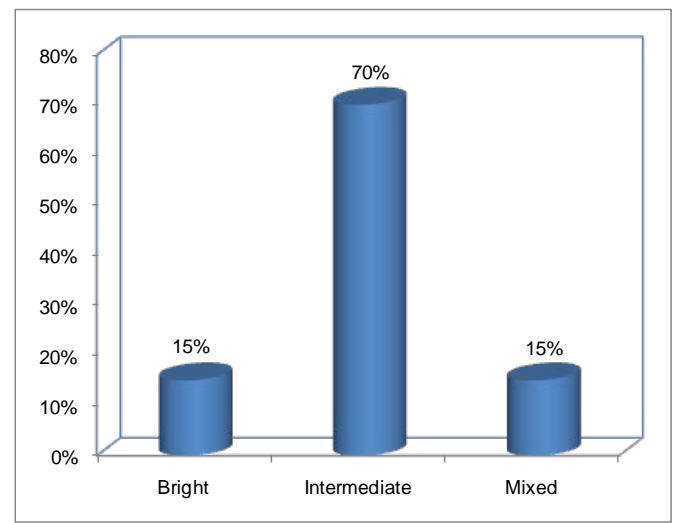

Fig 3: Intensities of the masses in $\mathrm{T} 1$.

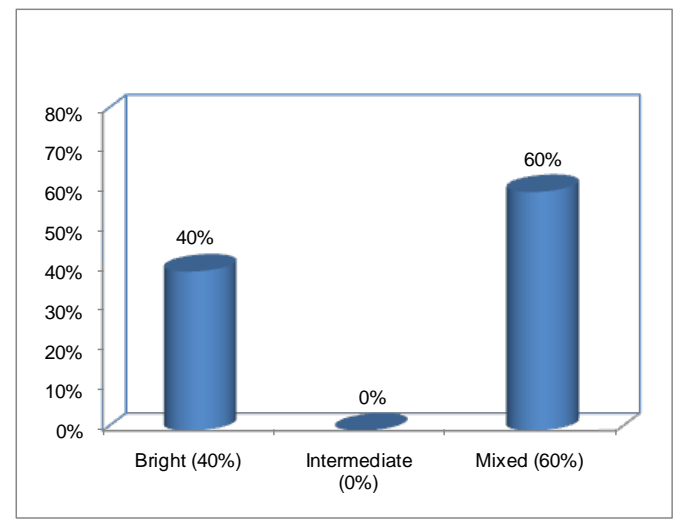

Fig 4: Intensities in $\mathrm{T} 2$. 


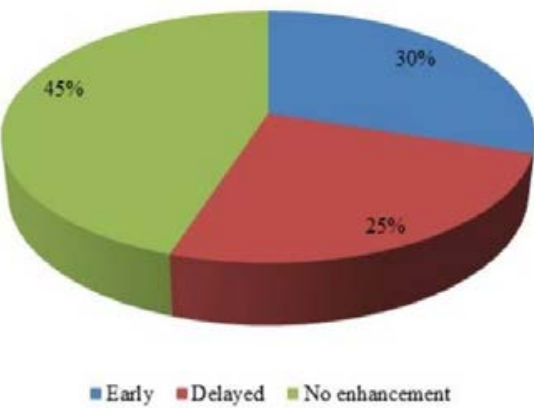

Fig 5: Contrast uptake by the masses.

The different ADC values for malignancy, the minimum was $0.2 \times 10-3 \mathrm{~mm} 2 / \mathrm{s}$ and maximum was $1.1 \times 10-3 \mathrm{~mm} 2 / \mathrm{s}$ with Mean +/- SD 0.74(+/-38722), while for benign masses, minimum was $0.2 \times 10-3$ $\mathrm{mm} 2 / \mathrm{s}$ and maximum was $2.7 \times 10-3 \mathrm{~mm} 2 / \mathrm{s}$ with Mean +/- SD 1.45 (+/-5463). (Table 4).

We compared the cases which was diagnosed by MRI as benign or malignant tumors as criteria mentioned before, with those diagnosed depending on the DWI and DCE-MRI, and the pathology which is considered the golden ruler.

For the sake of statistical evaluation, the borderline pathology of low potential malignancy (papillary serous cystadenoma) was categorized with the benign tumors.

Conventional MRI suggested malignant pathology in 12 tumors as being malignant. Seven were true positive (TP), two were border line, while three were benign and diagnosed as being malignant (FP). Conventional MRI suggested benign pathology in eight cases; seven were true negative (TN) while 1 malignant and diagnosed benign (FN). Diffusionweighted (DWI) magnetic resonance suggested malignancy in 14 tumors compared to only 8 stated by the pathology $(\mathrm{TP}=8),(\mathrm{FP}=6)$.

DCE-MRI was able to diagnose 7 malignant tumors (TP), one showed enhancement delay and was diagnosed as benign (FN). (Table 5), ( Figure 7).

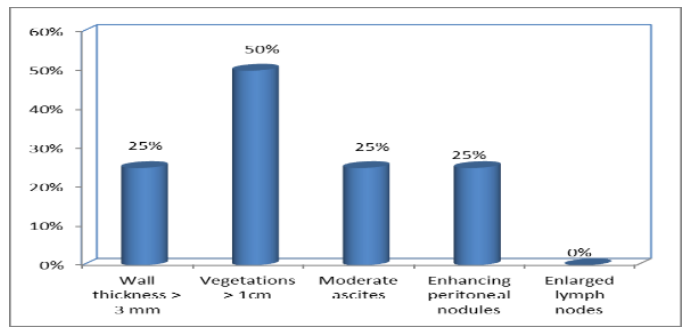

Fig 6: Criteria of malignancy in DCE MRI.

\begin{tabular}{|c|c|c|c|c|c|}
\hline \multirow[t]{2}{*}{ Histopathology } & \multicolumn{4}{|c|}{ DWI } & \multirow[t]{2}{*}{ ADC map } \\
\hline & b0 & b500 & b1000 & b1500 & \\
\hline $\begin{array}{l}\text { 1.Papillary serous } \\
\text { cystadenocarcinoma }(\mathrm{n}=3)\end{array}$ & intermediate & bright & bright & bright & intermediate \\
\hline $\begin{array}{l}\text { 2.Mucinous cystadenocarcinoma } \\
(\mathrm{n}=3)\end{array}$ & intermediate & bright & bright & bright & intermediate \\
\hline $\begin{array}{l}\text { 3.Juvenile granulosa cell tumor } \\
(\mathrm{n}=1)\end{array}$ & & bright & bright & bright & intermediate \\
\hline 4.Clear cell tumor $(n=1)$ & intermediate & bright & bright & bright & intermediate \\
\hline $\begin{array}{l}\text { 5.Borderline papillary serous } \\
\text { neoplasm }(\mathrm{n}=2)\end{array}$ & intermediate & bright & bright & bright & intermediate \\
\hline 6. Mature cystic teratoma $(n=2)$ & intermediate & bright & bright & bright & intermediate \\
\hline 7.Serous cyatadenoma $(n=2)$ & intermediate & Intermediate & Intermediate & Intermediate & Bright \\
\hline $\begin{array}{l}\text { 8.Peduculated subserous fibroid } \\
(\mathrm{n}=1)\end{array}$ & $\begin{array}{l}\text { Intermediate } \\
\text { Intermediate }\end{array}$ & $\begin{array}{l}\text { Inter-mediate } \\
\text { intermediate }\end{array}$ & $\begin{array}{l}\text { Bright } \\
\text { intermediate }\end{array}$ & $\begin{array}{l}\text { Bright } \\
\text { internediate }\end{array}$ & $\begin{array}{l}\text { Intermediate } \\
\text { Bright }\end{array}$ \\
\hline $\begin{array}{l}\text { 9.Papillary serous } \\
\text { cystadenofibroma }(\mathrm{n}=1)\end{array}$ & bright & bright & intermediate & intermediate & Bright \\
\hline $\begin{array}{l}\text { 10. Mucinous cystadenoma }(n=1) \\
\text { 11. inflammatory pelvic disease } \\
\text { (abscess) }(n=1) \\
\text { 12. Tubo-ovarian abscess }(n=1)\end{array}$ & $\begin{array}{l}\text { bright } \\
\text { intermediate } \\
\text { intermediate }\end{array}$ & $\begin{array}{l}\text { bright } \\
\text { intermediate } \\
\text { bright }\end{array}$ & $\begin{array}{l}\text { intermediate } \\
\text { intermediate } \\
\text { bright }\end{array}$ & $\begin{array}{l}\text { intermediate } \\
\text { intermediate } \\
\text { bright }\end{array}$ & $\begin{array}{l}\text { Bright } \\
\text { Bright } \\
\text { intermediate }\end{array}$ \\
\hline
\end{tabular}

Table 3: showing signal intensities of the pathological entities presented in the current study regarding DWI at different b-values and corresponding ADC map.

\begin{tabular}{|l|l|}
\hline \multicolumn{1}{|c|}{ Pathology } & \multicolumn{1}{c|}{ ADC values } \\
\hline $\begin{array}{l}\text { 1.Papillary serous cystadenocarcinoma }(\mathrm{n}=3) \\
\text { 2. Mucinous cystadenocarcinoma }(\mathrm{n}=3)\end{array}$ & $\begin{array}{l}(1.02 \times 10-3 \mathrm{~mm} 2 / \mathrm{s}) \\
(1.0 \times 10-3 \mathrm{~mm} 2 / \mathrm{s})\end{array}$ \\
\hline 3.Juvenile granulosa cell tumor $(\mathrm{n}=1)$ & $(0.8 \times 10-3 \mathrm{~mm} 2 / \mathrm{s})$ \\
\hline 4.Clear cell carcinoma $(\mathrm{n}=1)$ & $(1.2 \times 10-3 \mathrm{~mm} 2 / \mathrm{s})$ \\
\hline $\begin{array}{l}\text { 5.Borderline papillary serous neoplasm of low malignant } \\
\text { potential }(\mathrm{n}=2)\end{array}$ & $(1.1 \times 10-3 \mathrm{~mm} 2 / \mathrm{s})$ \\
\hline 6.Mature cystic teratoma(n=2) & $(0.8 \times 10-3 \mathrm{~mm} 2 / \mathrm{s})$ \\
\hline 7. Pedunculated subserous fibroid $(\mathrm{n}=2)$ & $(1.2 \times 10-3 \mathrm{~mm} 2 / \mathrm{s})$ \\
\hline 8. Serous cystadenoma $=(\mathrm{n}=2)$ & $(1.8 \times 10-3 \mathrm{~mm} 2 / \mathrm{s})$ \\
\hline
\end{tabular}




\begin{tabular}{|l|l|}
\hline 9.Tubo-ovarian abscess $(\mathrm{n}=1)$ & $(0.6 \times 10-3 \mathrm{~mm} 2 / \mathrm{s})$ \\
\hline 10.Papillary serous cystadenofibroma $(\mathrm{n}=1)$ & $(1.8 \times 10-3 \mathrm{~mm} 2 / \mathrm{s})$ \\
\hline 11.Mucinous cystadenoma $(\mathrm{n}=1)$ & $(2.8 \times 10-3 \mathrm{~mm} 2 / \mathrm{s})$ \\
\hline 12.inflammatory pelvic disease abscess $(\mathrm{n}=1)$ & $(1.2 \times 10-3 \mathrm{~mm} 2 / \mathrm{s})$ \\
\hline
\end{tabular}

Table 4: showing the different ADC values of the included masses.

\begin{tabular}{|c|c|c|c|c|c|c|c|c|c|}
\hline & \multicolumn{2}{|c|}{ Pathology } & \multirow[b]{2}{*}{ Sens. } & \multirow[b]{2}{*}{ Spec. } & \multirow[b]{2}{*}{ PPV } & \multirow[b]{2}{*}{ NPV } & \multirow[b]{2}{*}{ Accuracy } & \multirow[b]{2}{*}{ p-value } \\
\hline & & $\begin{array}{c}\text { Malignant } \\
(\mathrm{n}=8)\end{array}$ & $\begin{array}{l}\text { Benign } \\
(\mathrm{n}=12)\end{array}$ & & & & & & \\
\hline $\begin{array}{l}\text { Conventional } \\
\text { MRI }\end{array}$ & $\begin{array}{l}\text { Malignant } \\
(\mathrm{n}=12)\end{array}$ & 7 & 5 & \multirow{2}{*}{$87.5 \%$} & \multirow{2}{*}{$58.3 \%$} & \multirow{2}{*}{$58.3 \%$} & \multirow{2}{*}{$87.5 \%$} & \multirow{2}{*}{$70.0 \%$} & \multirow{2}{*}{0.130} \\
\hline & $\begin{array}{l}\text { Benign } \\
(\mathrm{n}=8)\end{array}$ & 1 & 7 & & & & & & \\
\hline \multirow[t]{2}{*}{$\begin{array}{l}\text { Diffusion- } \\
\text { weighted } \\
\text { (DWI) }\end{array}$} & $\begin{array}{l}\text { Malignant } \\
(\mathrm{n}=14)\end{array}$ & 8 & 6 & \multirow{2}{*}{$100.0 \%$} & \multirow{2}{*}{$50.0 \%$} & \multirow{2}{*}{$57.1 \%$} & \multirow{2}{*}{$100.0 \%$} & \multirow{2}{*}{$70.0 \%$} & \multirow{2}{*}{$0.048^{*}$} \\
\hline & $\begin{array}{l}\text { Benign } \\
(\mathrm{n}=6)\end{array}$ & 0 & 6 & & & & & & \\
\hline \multirow[t]{2}{*}{ DCE-MRI } & $\begin{array}{l}\text { Malignant } \\
(\mathrm{n}=7)\end{array}$ & 7 & 0 & \multirow{2}{*}{$87.5 \%$} & \multirow{2}{*}{$100.0 \%$} & \multirow{2}{*}{$100.0 \%$} & \multirow{2}{*}{$92.3 \%$} & \multirow{2}{*}{$95.0 \%$} & \multirow{2}{*}{$<0.001^{* *}$} \\
\hline & $\begin{array}{l}\text { Benign } \\
(\mathrm{n}=13)\end{array}$ & 1 & 12 & & & & & & \\
\hline
\end{tabular}

Table 5: Result of conventional MRI, DWI \& DCE.

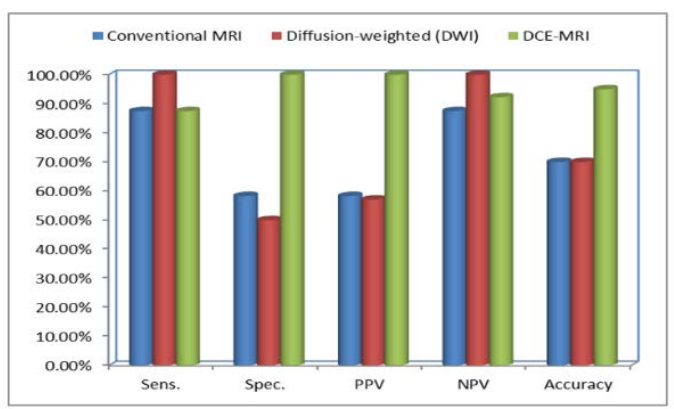

Fig 7: Result of conventional MRI, DWI \& DCE.

\section{Case 1}

39 year old female patient complaining of abdominal enlargement, menorrhagia, abdominal US showed right adnexal large heterogenous solid mass 15 x12 $\mathrm{cm}$.

\section{Description:}

Conventional MRI images a, b, c confirmed the presence of huge pelvi-abdominal complex adnexal mass abutting the uterine fundus anteriorly. It shows heterogeneous intensity at $\mathrm{T} 1$ and $\mathrm{T} 2$,. Low to intermediate signal on DWI, ADC value of the tumor was $1.1 \times 10^{-3} \mathrm{~mm}^{2} / \mathrm{s}$.

DCE MRI, the mass shows mild heterogeneous contrast enhancement on the post-contrast studies delayed peak of initial uptake at 240 s, MRE 74\%, and plateau curve pattern ( Figure 8).

\section{Pathology:}

Pedunculated fundal subserous myoma (fibroid)

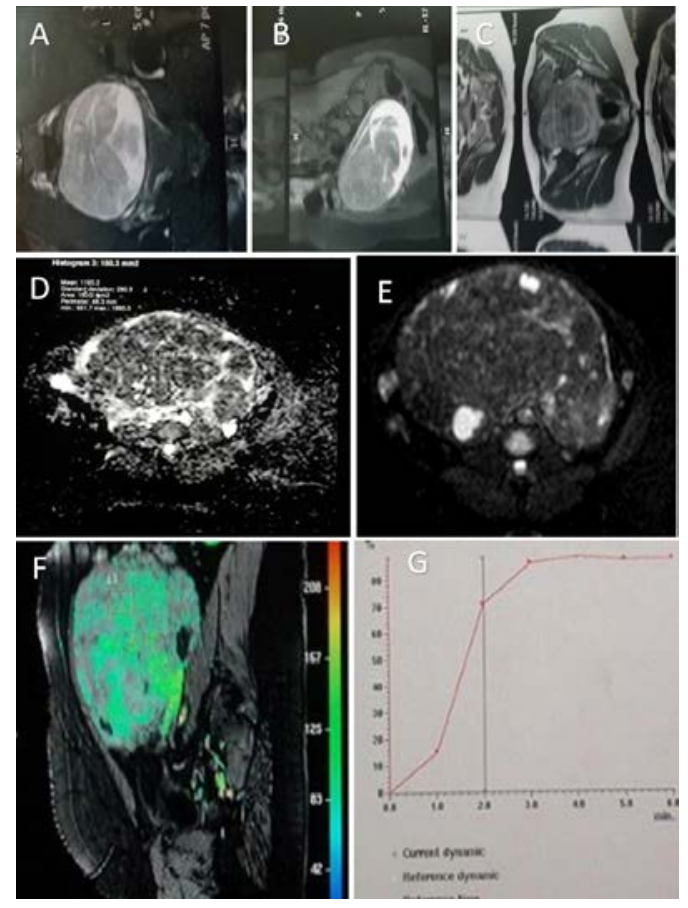

Fig 8: (A) Coronal T2, (B) Sagittal T2-WI, (C) axial T1-WI,(D and E) DWI and ADC, (F and G) DCEMRI.

\section{Case (2)}

60 year old female patient came complaining of abdominal enlargement and loss of weight.

Pathology: Left ovarian papillary serous cystadenocarcinoma ( Figure 9). 

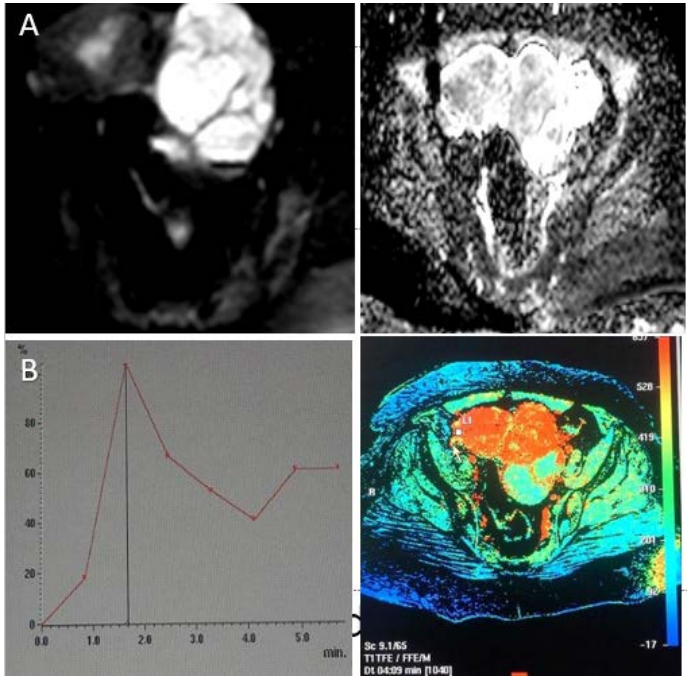

Fig 9: DWI \& ADC (A): High signal on DWI with low to intermediate signal on the corresponding ADC maps. ADC value of the tumor was $0.5 \times 10^{-3} \mathrm{~mm}^{2} / \mathrm{s}$. DCE-MRI (B): The lesion showed heterogeneous marked contrast enhancement with early time to peak at $90 \mathrm{~s}$, MRE 90\%, and early wash out. MRI suggesting left adnexal malignant mass.

\section{DISCUSSION}

Conventional MRI can reveal morphologic characteristics of different pelvic masses such as papillary projections, nodularity, and solid portions, but none of these criteria reliably distinguish between lesion types. MRI with contrast can add value to distinguish between lesions types. ${ }^{9,10}$

DWI can characterize types of adnexal lesions. ${ }^{11}$

In this study we had performed conventional MR sequences, DWI and DCE-MR imaging regarding their diagnostic value to distinguish complex adnexal masses.

MRI was important in morphological features, followed by evaluation of the masses with DWI imaging and dynamic post contrast (DCE) series.

DWI had shown $100 \%$ sensitivity in its individual performance during the assessment of the included adnexal masses, with low specificity (50\%). Teratomas $=2$, tubo-ovarian abscess $=1$, border line papillary serous neoplasm $=2$ and pedunculated subserous fibroid=1 revealed hyperintense signals (restriction DWI) (FP).

In 2011, Thomassin\& Naggara ${ }^{11}$ results of MRI performed on pelvic masses revealed that, hypointensity on T2WI and free DW in the soft tissue part of the heterogeneous large pelvic masses may be indicative of benign lesion. In addition, ADC values in benign tumors are due to fibers within it.

Takeuchi ${ }^{12}$ in 2010 performed study included 49 ovarian tumors (39 malignant/borderline neoplasia, and 10 benign), it stated that the solid part of all the 39 malignant tumors showed homogenous or heterogeneous high intensity on DWI, whereas only 3 of the 10 benign tumors ( 3 thecomas) showed high intensity, ADC in 39 malignant tumors $1.03 \times 10-3$ $\mathrm{mm} 2 / \mathrm{s}$ and was significantly lower than that of the 10 benign tumors $1.38 \times 10-3$, they concluded low DWI and high ADC intensity may suggest benign lesion. That suggestion is accepted according to this study regard that high cellular masses (teratomas, fibroid, tubo-ovarian abscess) which revealed high signal intensity at DWI (DW restriction).

Zhang ${ }^{10}$ in 2012 performed study on 91 cases, 202 pelvic lesions; using ADC map for the soft tissue part of heterogeneous masses to distinguish types of pelvic lesions.

It revealed that diagnostic importance for DWI to discriminate the epithelial ovarian tumors with solid portion, excluding endometriomas, teratomas and pure cystic adenomas from the analysis. That exclusion may have elevated the specificity. But we cannot apply it because our analysis is a prospective study.

Zhoa SH and colleagues ${ }^{13}$ performed study in 2014 to investigate role of MRI series to distinguish borderline from malignant epithelial ovarian tumors, the study included 60 borderline epithelial ovarian tumor (BEOTs) in 48 patients and 65 malignant malignancy (MEOTs) in 54 patients.

It resulted in, almost MEOTs showed diffusion restriction, whereas most of BEOTs showed low or moderate signal intensity. ADC of solid part of BEOTs $(1.562 \pm 0.346 \times 10-3 \mathrm{~mm} 2 / \mathrm{s})$. In MEOTs $(0.841 \pm 0.209 \times 10-3 \mathrm{~mm} 2 / \mathrm{s})$.

Our study included only two borderline tumor (papillary serous neoplasm), showed moderate to low restricted diffusion on DWI \& high ADC.

A study was done by Nasr, Abbas and Khalifa 2014

14 described that a contrast pattern of plateau curve had been shown in 16 masses 11 of them were histopthologically malignant. In view of their analysis; the time to peak ranged between 30 to $70 \mathrm{~s}$ with an average $53 \mathrm{~s}$ and MRE\% ranged from 100\% to $180 \%$ with an average of $130 \%$ in malignant masses. In Nasr et al study benign lesions, showed time of peak range of 70 to $110 \mathrm{~s}$ with an average $92 \mathrm{~s}$, and MRE\% ranged of $40 \%$ to $140 \%$ with an average of $73 \%$. According to them, MRI sensitivity $=99.9 \%$ and of DCE-MRI $=60 \%$. DCE specificity $=91 \%$ and conventional MRI $=58.3 \%$. DCE accuracy $=77 \%$ and MRI $=73.9 \%$.

This study revealed conventional MRI sensitivity on individual basis was the same as DCE-MRI (87.5\%). DCE specificity $=100 \%$ and conventional MRI $=58.3 \%$. DCE accuracy $=95 \%$ and MRI $=70 \%$. The malignant lesions, revealed contrast time to peak ranged from 60 to 90 seconds. It also significant early uptake. One malignant mass was misdiagnosed as benign (mucinous cystadenocarcinoma). It showed delayed enhancement. The benign lesions showed time of peak range from 90 to 120 seconds. 


\section{CONCLUSION}

MRI can help to distinguish between types of different adnexal masses. However, the final diagnosis based on MRI is frequently not possible until surgical exploration and histological examination are performed. MR also provides useful information for diagnosis of various ovarian masses. Conventional MRI revealed morphologic data as solid part, mural nodule, septations, T1 and T2WIs, appearances of the mass lesion. By conventional MRI, we cannot reliably differentiate the type of adnexal lesion.

DWI can add diagnostic value for MR criteria to differentiate types of adnexal lesions. ADC can be also displayed. Diffusion restriction revealed high signal on DWI and lower on ADC. DWI increased the sensitivity, but didn't improve the specificity or the accuracy, while addition of DCE-MRI increased the specificity (100\%), accuracy (95\%).

There were limited MRI machines of 1.5 tesla and limited sample size which affected the values presented by the DW imaging and even may underestimate its analysis in the diagnosis of different masses. We recommend another extended broad analysis with 3 Tesla machines to re-evaluate the disadvantage of the DWI as it could be considered a potential alternative of contrast enhanced sequences.

\section{REFERENCES}

1- Akram M. Shaaban, Maryam Revanzi, et al. Ovaian tumours, in Diagnostic radiology, Gynecology, chapter 5 page from 40 to 182, Amirsys, El sevier, 2 nd edition 2015

2- Thomassin-Naggara I, Aubert E, Rockall A, et al, Adnexal Masses:Development and preliminary Validation of an MR Imaging Scoring System. Radiology, 2013; 267(2):432-43.

3- Kyriazi S, Kaye S and M. deSouza N. Imaging ovarian cancer and peritoneal metastases, current and emerging techniques Clin. Oncol. 2010; 7: 381-93.

4- Motoshima s, Irie H, and Kudo S. Diffusion MR Imaging in gynecologic cancer. J Gynecology Oncology. 2011 22(4):275-8.

5- Kitajima K, Yamasaki E, Kaji Y, et al. Comparison of DWI and PET/CT in evaluation of lymph node metastasis in uterine cancer. World J Radiol. 2012; 28:4(5): 207-14.

6- Lee KR and Young RH. The distinction between primary and metastatic mucinous carcinomas of the ovary:gross and histologic findings in 50 cases. Am J Surg Pathol. 2003;27(3):281-92.

7- Luna A, Ribes R, A.Soto J. Diffusion MRI outside the brain, Chapter 9, Use of DWI in female pelvis, Springer, Berlin, 2011; P.180.

8- Lyer VR and Lee SI. MRI/CT and PET/CT for ovarian cancer detection and adnexal lesion characterization. American Journal of Roentgenology, 2010; 194(2)311-21.

9- Zhang H, Zhang GF, He ZY, et al. Prospective evaluation of $3 \mathrm{~T}$ MRI findings for Primary
Adnexal Lesions and Comparison with final histological diagnosis. Archives of gynecology and obstetrics. 2014; 289:357-64.

10-Zhang P, Cui P, Li W, et al. Diagnostic accuracy of diffusion-weighted imaging with conventional MR imaging for differentiating complex solid and cystic ovarian tumors at $1.5 \mathrm{~T}$, Zhang et al. World Journal of Surgical Oncology. 2012,10:237.

11- Thomassin-Naggara I, Toussaint I, Perrot N, et al. Charachterization of complex adnexal masses: value of adding perfusion-and diffusion weighted MR imaging to conventional MR imaging. Radiology, 2011;258(3); 793:803.

12-Takeuchi M, Matsuzaki $\mathrm{K}$ and Nishitani $\mathrm{H}$. Diffusion-Weighted Magnetic Resonance Imaging of Ovarian Tumors: Differentiation of Benign and Malignant Solid Components of Ovarian Masses. J Comput Assist Tomogr. 2010; 34: $173-6$

13- Zhao SH, Qiang JW, Zhang GF, et al. MRI in differentiating ovarian borderline from benign mucinous cystadenoma: pathological correlation. J Magn Reson Imaging. 2014; 39(1):162-6.

14- Nasr I, Hamid I, Abbas I, et al. Dynamic contrast enhanced MRI in correlation with diffusion weighted DW MR for characterization of ovarian masses. The Egyption Journal of Radiology and nuclear Medicine. 2014; 45 (3): 975-85 